\title{
Spatial Information in local society’s cultural conservation and research
}

\author{
Jr-Jie Jang ${ }^{\text {a }}$, Hsiung-Ming Liao ${ }^{a}$, I-Chun Fan ${ }^{\mathrm{a}, *}$ \\ ${ }^{a}$ Center for Geographic Information Science, Research Center for Humanities and Social Sciences, Academia Sinica, Taiwan - \\ (roger, veevee,)@gate.sinica.edu.tw, mhfanbbc@ccvax.sinica.edu.tw
}

KEY WORDS: Time-spatial information, GIS, Cultural Resources, Cultural Conservation

\begin{abstract}
:
Center for Geographic Information Science, Research Center for Humanities and Social Sciences,Academia Sinica (GIS center), Coordinate short-, medium-, and long-term operations of multidisciplinary researches focusing on related topics in the sciences and humanities. Based on the requirements of multi-disciplinary research applications, sustain collection and construction of sustaining and unifying spatial base data and knowledge and building of spatial data infrastructure.

Since the 1990s, GIS center build geographic information platform: "Time and space infrastructure of Chinese civilization" (Chinese Civilizationin Time and Space, CCTS) and "Taiwan History and Culture Map" (Taiwan History and Culture in Time and Space, THCTS) . the goal of both system is constructing an integrated GIS-based application infrastructure on the spatial extent of China and Taiwan, in the timeframe of Chinese and Taiwanese history, and with the contents of Chinese and Taiwanese civilization.
\end{abstract}

Base on THCTS, we began to build Cultural Resources GIS(CRGIS, http://crgis.rchss.sinica.edu.tw/) in 2006, to collect temples, historic Monuments, historic buildings, old trees, wind lions god and other cultural resource in Taiwan, and provide a platform for the volunteers to make for all types of tangible, intangible cultural resources, add, edit, organize and query data via Content Management System(CMS) .

CRGIS collected aggregated 13,000 temples, 4,900 churches. On this basis, draw a variety of religious beliefs map-multiple times Temple distributions, different main god distributions, church distribution. Such as Mazu maps, Multiple times temple distributions map (before 1823, 1823-1895,1895-1949,1949-2015 years) at Taijiang inner sea areas in Tainan.

In Taiwan, there is a religious ritual through folk activities for a period ranging from one day to several days, passing specific geospatial range and passes through some temples or houses. Such an important folk activity somewhat similar to Western parade, called " raojing " , the main spirit is passing through of these ranges in the process, to reach the people within bless range, many scholars and academic experts's folk research are dependent on such spatial information. 2012, GIS center applied WebGIS and GPS to gather raojing activities spatial information in cooperation with multi-units, aggregated seven sessions, 22 days, 442 temples had pass through . The atlas also published named 【Atlas of the 2012 Religious Processions in the Tainan Region】 in 2014.

we also applied national cultural resources data form relevant government authorities, through the metadata design and data processing(geocoding), established cultural geospatial and thematic information ,such as 800 monuments, 1,100 historic buildings and 4,300 old trees data

In recent years, based on CRGIS technology and operational concepts, different domain experts or local culture-ahistory research worker/team had to cooperate with us to establish local or thematic material and cultural resources. As in collaboration with local culture-history research worker in Kinmen County in 2012, build Kinmen intangible cultural assets - Wind Lion God ,set metadata and build 122 wind lion god 's attribute data and maps through field survey, it is worth mention such fieldwork data integrity is more than the official registration data form Kinmen National Park, the number of is wind lion god more than 40; in 2013,we were in cooperation with academic experts to establish property data and map of the theatre during the Japanese colonial era in Taiwan, a total of 170 theatres ; we were in cooperation with Japanese scholars, used his 44 detaile field survey data of sugar refineries during the Japanese colonial era in Taiwan ,to produce a sugar refineries distribution map and extend to a thematic web(http://map.net.tw/) [The Cultural Heritage Maps of Taiwan Suger Factories in a Century]site according to CRGIS independent cultural concept.

Deployment and operation of the CRGIS, the meaning is not only build the thematic GIS system ,but also contain these concepts: Open Data, Wikipedia ,Public Participation, and we provide an interactive platform with culture resource data and geospatial technology.

In addition to providing these reference material for local culture education, local cultural recognition, but to further cooperate with scholars, academic experts , local culture-history research worker / team, accumulated rich record of the past, research results, through the spatial database planning, data processing(ex. geocoding), field survey, geospatial materials overlapping, such as nesting geospatial technology to compile the cultural information and value-added applications.

* Corresponding author 


\section{INTRODUCTION}

Center for Geographic Information Science, Research Center for Humanities and Social Sciences,Academia Sinica (GIS center), Coordinate short-, medium-, and long-term operations of multidisciplinary researches focusing on related topics in the sciences and humanities. Based on the requirements of multidisciplinary research applications, sustain collection and construction of sustaining and unifying spatial base data and knowledge and building of spatial data infrastructure.Since the 1990s, GIS center build two spatio-temporal framework: "Time and space infrastructure of Chinese civilization" (Chinese Civilizationin Time and Space, CCTS)(Figure 1) and "Taiwan History and Culture Map" (Taiwan History and Culture in Time and Space, THCTS)(Figure 2) . the goal of both system is constructing an integrated GIS-based application infrastructure on the spatial extent of China and Taiwan, in the timeframe of Chinese and Taiwanese history, and with the contents of Chinese and Taiwanese civilization.

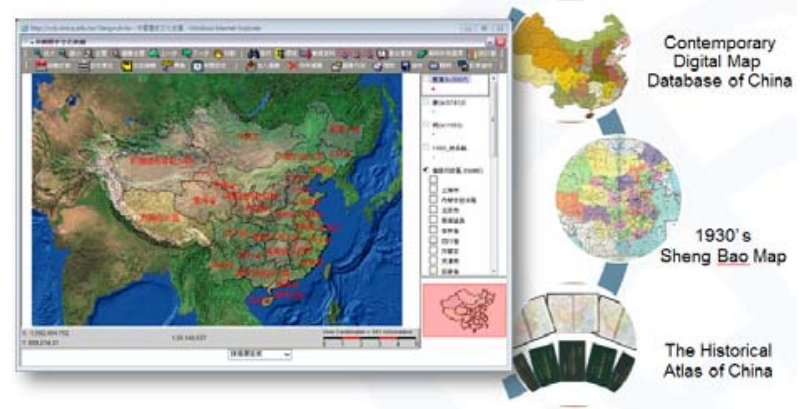

Figure 1 Chinese spatio-temporal framework-Historical CCTS

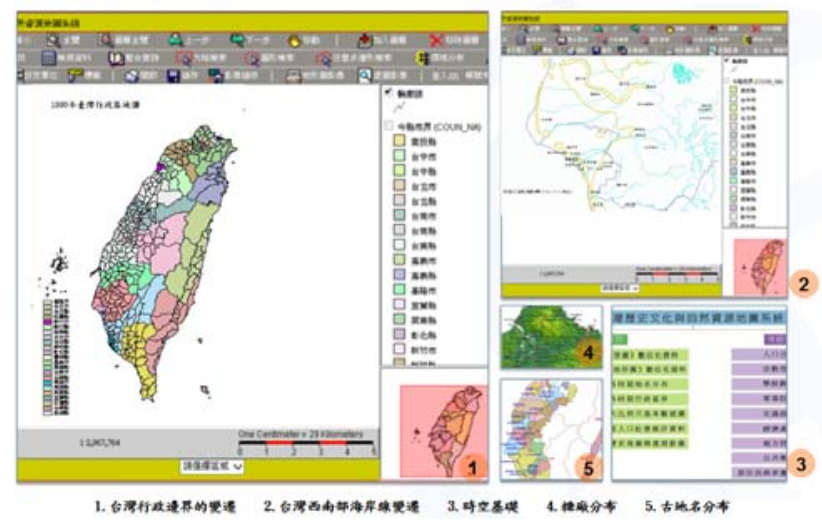

Figure 2 Taiwan's spatio-temporal framework- THCTS

In Taiwan, according to statistics of the Ministry of Culture, there are 2,071 tangible cultural assets(include 820 monuments ,1,208 historic buildings,43 archeological sites) and 420 intangible cultural assets(include 266 traditional art, 154 folk art, handicrafts and related artifacts. In addition, there are more cultural asset don't protect by Cultural Heritage Preservation Law. For example, there are 1,793 protected trees in Taipei, depends on trees's size and age.These historical and cultural objects, we call cultural resources, and considers the need for record and conservation.

A broad definition of cultural resources, including the various types of tangible cultural assets,like temples, monuments, historic buildings, college, old trees and intangible cultural assets like religious and folk activities, art, drama and so
on.And not necessarily to go through legal procedures specify or login.

Base on THCTS, we began to build Cultural Resources GIS(CRGIS, http://crgis.rchss.sinica.edu.tw/) in 2006, to collect temples, historic Monuments, historic buildings, old trees, wind lions god and other cultural resource in Taiwan.

\section{CRGIS INTRODUCTION}

CRGIS provide a platform for the volunteers to make for all types of tangible, intangible cultural resources, add, edit, organize and query data via Content Management System(CMS) .

CRGIS(Figure 3) to "spatio-temporal framework" as the main concept, with GIS technology, with various types of image map data. It aims to provide a complete spatio-temporal information platform, able for user to , add, edit, organize and query, and the image presented for all types of tangible and intangible cultural resourcesin a way.

CRGIS In addition to detailed information on each record property a cultural resources, including text, photos, website links and other information, but also the integration of WebGIS interface, providing users with different conditions, such as geographic region, building's year, and different main god to do a spatial query.

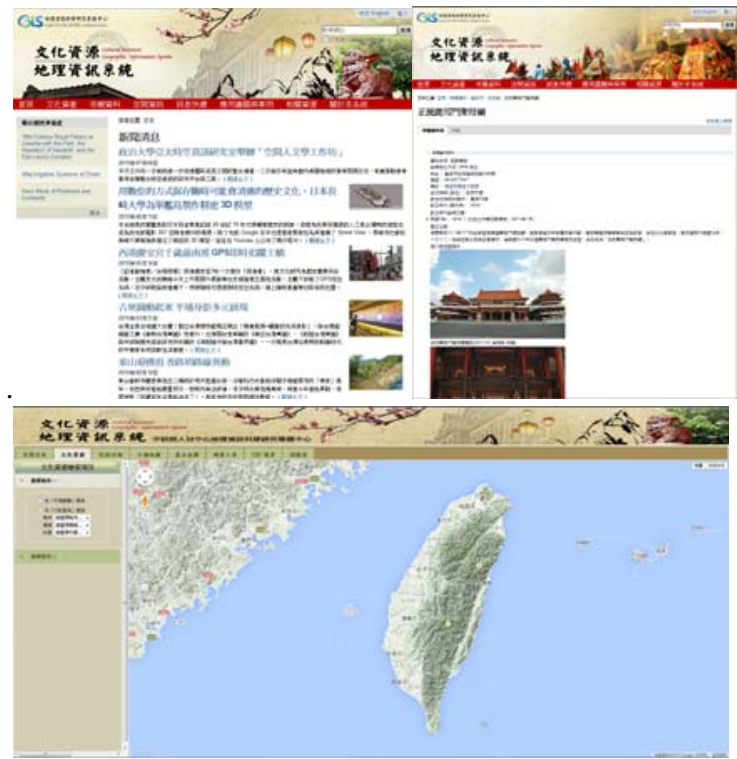

Figure 3 CRGIS website

In 2011 to 2012, further a thematic research program,Academia Sinica,we were in cooperation with local cultural researcher / groups to survey temples resources for the southern counties and offshore islands total of nine counties.

In recent years, based on CRGIS technology and operational concepts, different domain experts or local culture-ahistory research worker/team had to cooperate with us to establish local or thematic material and cultural resources. CRGIS collected aggregated 13,000 temples, 4,900 churches, 122 Wind Lion God (Kinmen country intangible cultural assets), 800 monuments, 1,100 historic buildings and 4,300 old trees, 170 theatres during the Japanese colonial era in Taiwan, 44 sugar refineries during the Japanese colonial era in Taiwan. 
And On this basis, draw a variety of religious beliefs mapmultiple times Temple distributions, different main god distributions, church distribution. Such as Mazu maps(Figure 4), Multiple times temple distributions map (before 1823, 18231895,1895-1949,1949-2015 years) at Taijiang inner sea areas in Tainan.



Figure 4 Mazu map

\subsection{Metadata}

Basic concept of virtual spatio-temporal framework is that have five core elements of information: Human, Event, Time, Place and Object. And those elements all can put into the virtual spatio-temporal framework with 3 dimention:X,Y and t(Time) (Figure 5) 。

Therefore, when creating cultural resources metadata, taking into account the five core elements of information. For example, we build temple'sthe metadata included year of the building , the main god of the temple, folk ritual category and date, building exterior photos, location with coordinate, references, etc.



Figure 5 five core elements of information in spatio-temporal framework
In addition, due to cultural resources, it has a rich historical and cultural background and knowledge, in the long period of development, often have different terms to describe the same thing matters, namely sematic, which should be especially when set metadata attention.

For example, in CRGIS temple database, the original name of up to more than 1,200 kinds of gods, but many names refer to the same god, after semantic normalization process, reduce the number to 200 kinds(Figure 6). This follow-up to the user's search query results, it improved a lot of accuracy.

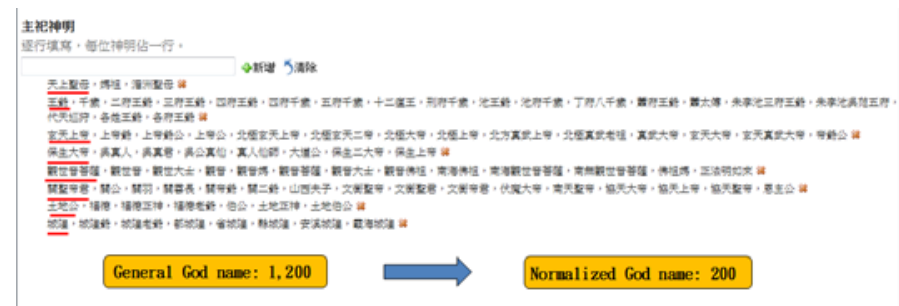

Figure 6 normalized god name

\subsection{Data geocoding and Fieldsurvey}

CRGIS's data all have spatial information, but not all the data beginning with spatial coordinates, so depending on the different data source and cooperative partner, has different geocoding way to make these data have spatial information(coordinates).

For example: monuments, historic buildings and churches raw materials, mostly recording vis .xls (excel) filetype,which contains the address field. In Taiwan, Ministry of the interior(MOI) provided Address Location Services(Taiwan Geospatial One-Stop Portal,TGOS), so we can quickly give the geographic coordinates for this type of cultural resources information through a batch geocoding operations.Of course,we also can use google solution,but its location's accuracy is not better than TGOS.

Theaters during the Japanese colonial era in Taiwan still remaining today except for a few, can confirm the location through fieldwork, many theaters have been destroy or relocated in 40, 50 years ago. It was confirmed that spatial location must sort through the historic literature and historic map.Academia Sinica accumulated THCTS and "The Map and Remote Sensing Imagery DigitalArchive Project" research result (http://gis.rchss.sinica.edu.tw/mapdap/),providesr researchers to label (geo-digitizing) theater's location. (Figure 7) by GIS software 。

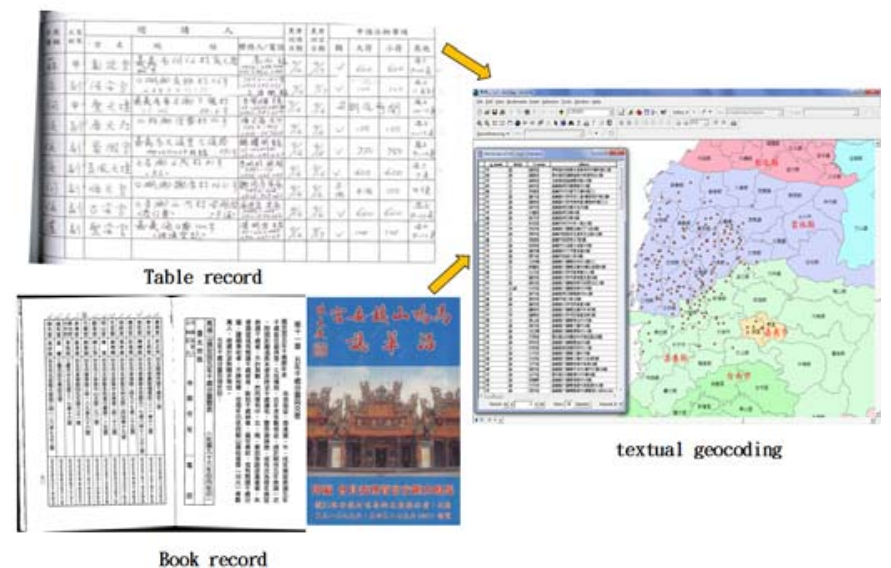

Figure 7 textual geocoding 
Temples and wind lions god, mostly fieldwork is required in order to confirm location, so GIS center first organized a series of workshops about GIS and GPS training before fielsurvey work.

Since CRGIS take VGI (Volunteered geographic information) mode, the voluntary cooperation of cultural preservation or investigation team, could to fill research survey results into CRGIS online,through education and training after the workshop.

\section{DIGITAL PRESERVATION VIA SPATIAL INFORMATION TECHNOLOGY}

Diverse cultural resources of each type has a different presentation, preservation methods also will be different, the following describes three ways to save a digital preservation via spatial technology.

\subsection{Activities tracklog}

In Taiwan, there is a religious ritual through folk activities for a period ranging from one day to several days, passing specific geospatial range and passes through some temples or houses. Such an important folk activity somewhat similar to Western parade, called " raojing " , the main spirit is passing through of these ranges in the process, to reach the people within bless range, many scholars and academic experts's folk research are dependent on such spatial information. 2012, GIS center applied WebGIS and GPS to gather raojing activities spatial information in cooperation with multi-units.

We put GPS equipmenet on a sin-kio(神轎)(Figure 8)-means god's chair that can moving via wheels or people. And through GSM technology instantly it displays sin-kio 's(神轎) realtime location online the webpage (Figure 9)
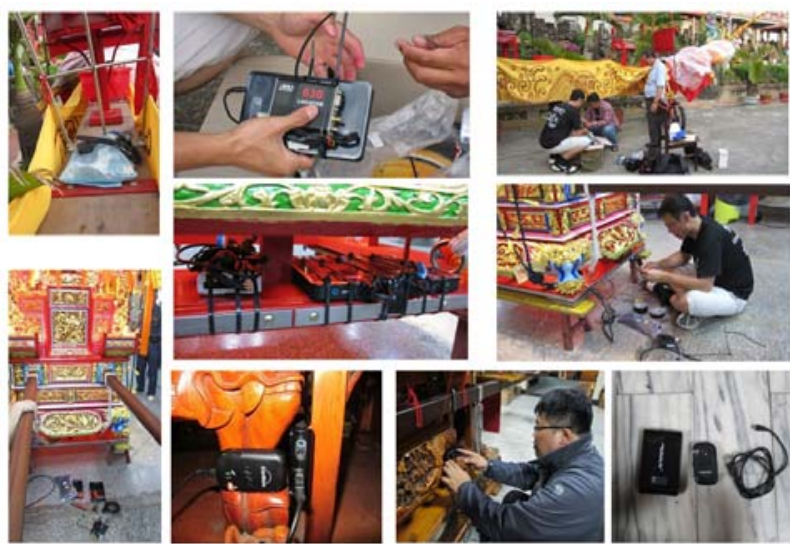

Figure 8 GPS equipment on a sin-kio(神轎)
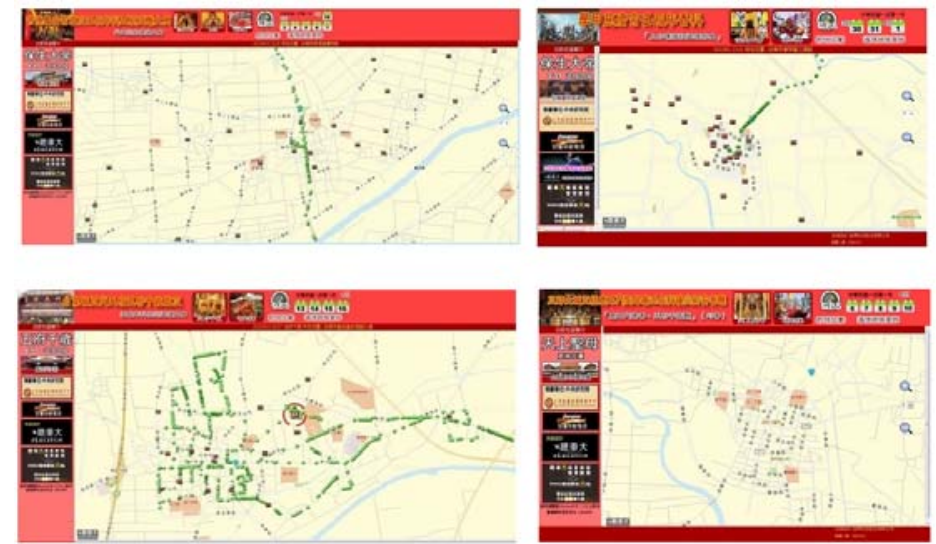

Figure 9 sin-kio’s(神轎) realtime location online

It aggregated seven sessions, 22 days, 442 temples had pass through . The atlas also published named 【Atlas of the 2012 Religious Processions in the Tainan Region】 in 2014(Figure 10).
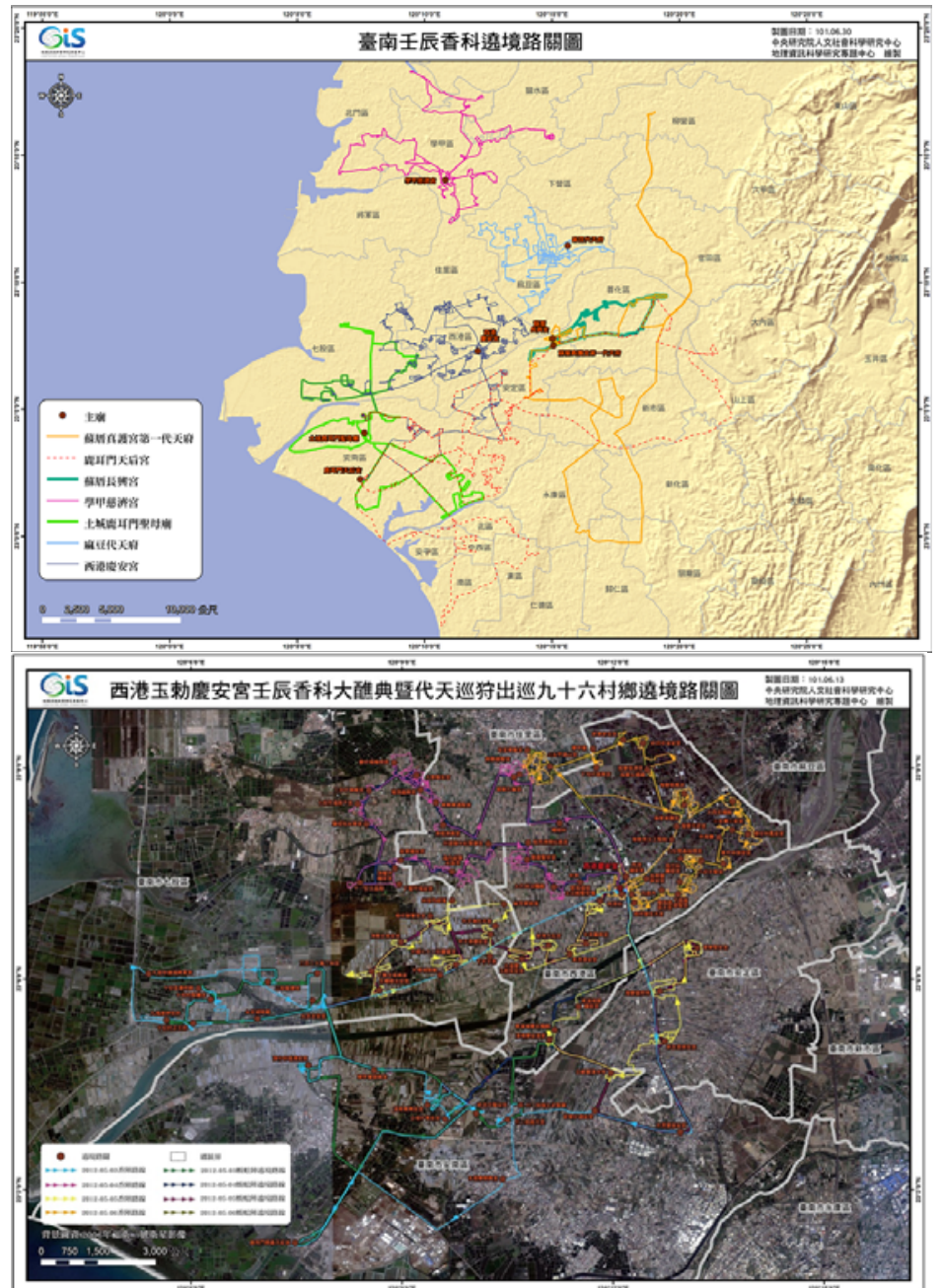

Figure 10 Atlas of the 2012 Religious Processions in the Tainan Region

\subsection{Street Panorama}

We use Vehicle Mobile Mapping System to record folk activities. Because Vehicle Mobile Mapping System integrates 
3D video image with GIS database and captures $360^{\circ}$ video with positional information while driving,and use camera vector technology assigns 3D coordinates to video images.So each video fram has $360^{\circ}$ spatial information(Figure 11), while video began a run, the fram can be rotated, zoom in, zoom out, and measure the length, area. This mobile mapping system technology for long-distance or quickly record issue of cultural assets have fairly significant benefit. (http://map.rchss.sinica.edu.tw/720vr/360video/da/index.html )

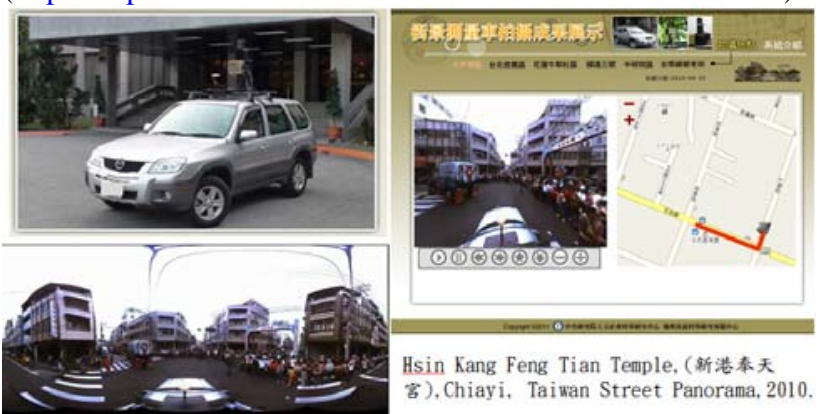

Figure 11 Hsin Kang Feng Tian Temple,(新港奉天 宮),Chiayi, Taiwan Street Panorama,2010.

\subsection{Aerial Panorama}

In Taiwan, the temple buildings, where many of the early settlements development, mostly in local temples extended outward as the center, a local religious center. Through UAV (Unmanned Aerial Vehicle) low altitude(about 100 300 m height) records, can be observed through a bird's eye view of a clear structure of the temple and the distribution relationship with the houses, the streets surrounding space. GIS center 's cooperative partner created So-chhu Tiong-heng kiong (蘇厝長興宮), Tainan, Taiwan Aerial Panorama in 2012. (Figure 12) ( http://www.360cities.net/image/-tainan-2 ) 。


Figure 12 So-chhu Tiong-heng kiong (蘇厝長興 宮),Tainan, Taiwan Aerial Panorama,2012.

In addition to building distribution spatial information, the folkevents at the temple during the use of UAV carried a record of people activity, also belongs to a precious cultural assets. GIS center 's cooperative partner created Hsin Kang Feng Tian Temple, (新港奉天宮), Chiayi, Taiwan Aerial Panorama in 2010. (Figure 13)。
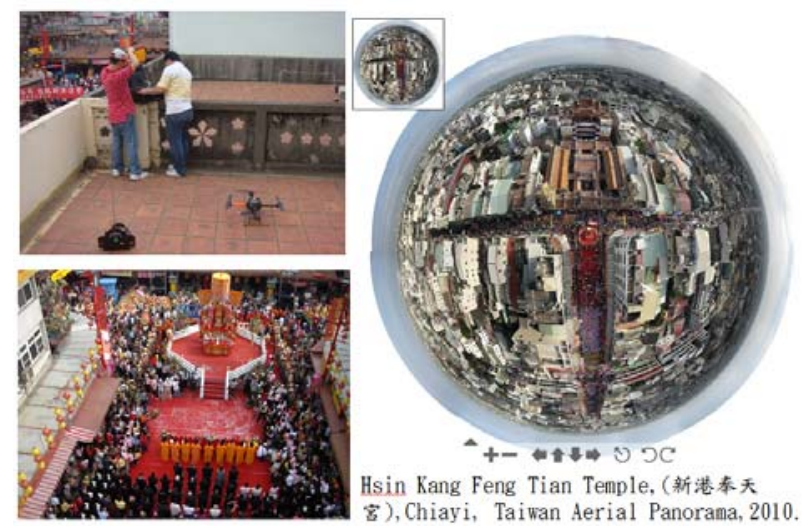

Figure 13 Hsin Kang Feng Tian Temple,(新港奉天宮),Chiayi, Taiwan Aerial Panorama,2010.

\subsection{Observe Spatial-Temporal Phenomenon}

When cultural resources had digital preservation, to establish a database, the next step can be observed and studied. Whether it is academic research, education or place of local phenomena observed, get a lot of help and benefits through spatial information technology.

Mazu temples's distributions in Tainan, Taiwan as follows: Select s Tainan's Mazu temples from CRGIS temple database, as it has spatial-temporal characteristics, it can be converted from general static chart into 1930's of Tainan Mazu temple distribution map (Figure 14)。

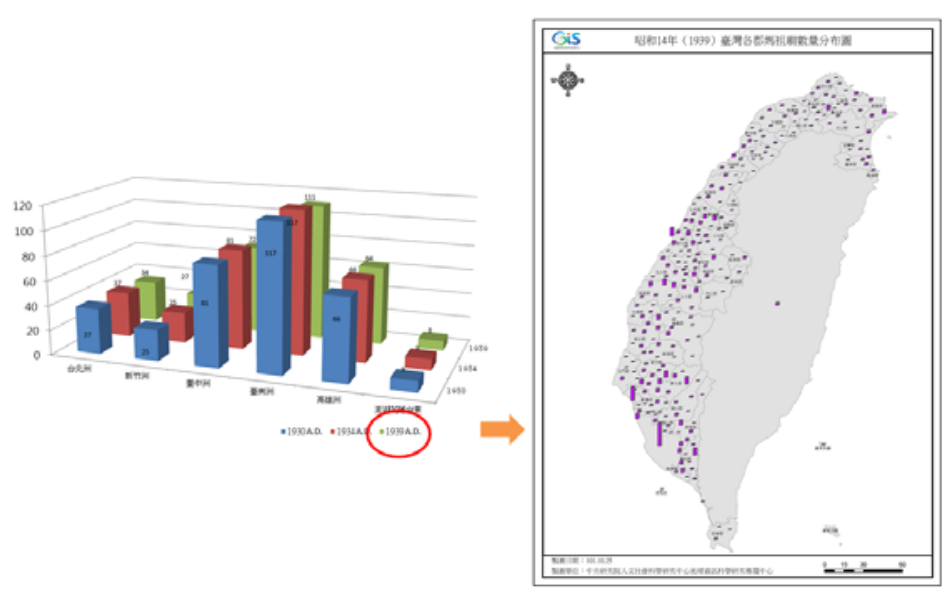

Figure 14 from static chart to map

Through GIS to overlap coastline and Mazu Temple in the 17th and 18th Centuries, Tainan, Taiwan, can be found in the majority of the Mazu temples distribution were along the coastline or the port, and there is a tendency to migrate to mountain area eastward gradually(Figure 15). 


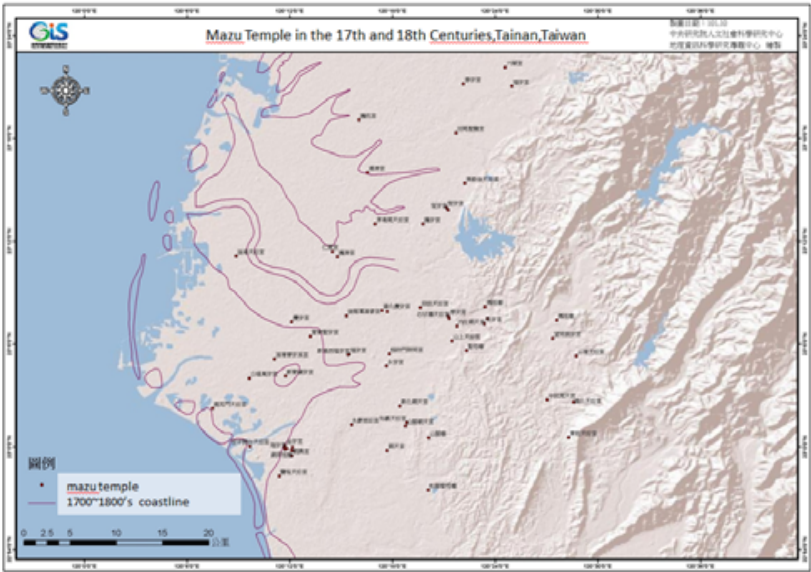

Figure 15 coastline and Mazu Temple in the 17th and 18th Centuries,Tainan,Taiwan overlapping

This year, GIS center has developed a new 4D GIS platform SinicaView, similar Gooele Earth's interface, with simple, beautiful, and other characteristics. And smoothly rendered 3D model, lidar pointcloud data and other filetypes of cultural preservation archives (Figure 16) 。 We will continue to integrate research results and data presented in this platform and provides researchers and the general public user for free download and use. (http://3dgis.rchss.sinica.edu.tw ) 。

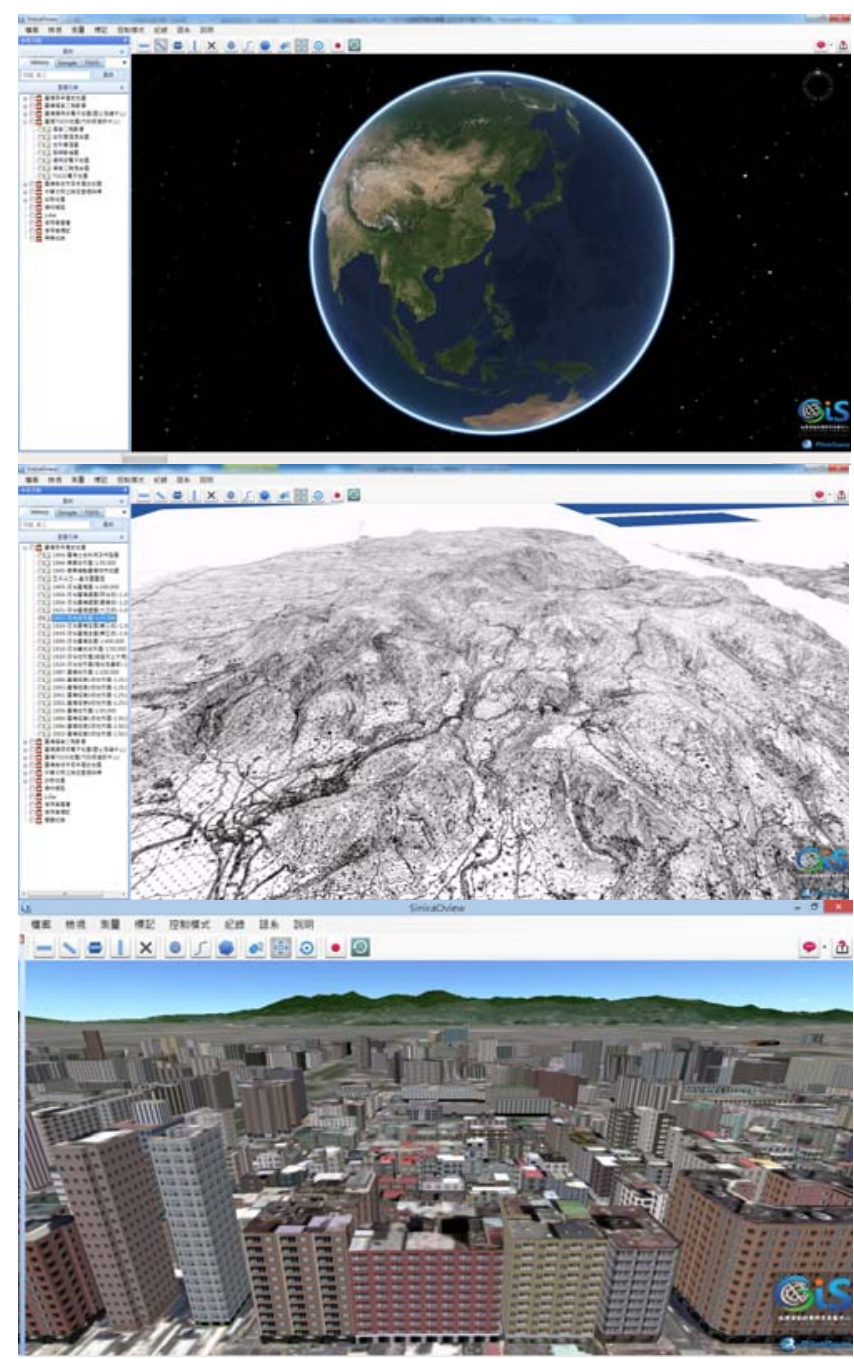

Figure 16 4D GIS platform-SinicaView

\section{DISCUSSIONS AND CONCLUSIONS}

In recent years GIS center applies a lot of spatial information technology in the cultural preservation of local society, and created and accumulated many valuable, diverse spatial information and experience.

Deployment and operation of the CRGIS, the meaning is not only build the thematic GIS system ,but also contain these concepts: Open Data, Wikipedia ,Public Participation, and we provide an interactive platform with culture resource data and geospatial technology.

In this process, we successfully imported VGI mode, which is different from the traditional large-scale project requires huge funds to conduct a large-scale areas cultural preservation or survey work. These volunteer of scholars, academic experts, local culture-history research worker / team, even in the rare case of few or no funds, because interest or research needs, can participate in a long-term investigation of cultural preservation and updating the data.

This year,GIS center have a new 4D GIS platform-SinicaView, that have saptio-temporal framework, the intrinsic of the social services and the interdisciplinary research application platform. SinicaView provide a "space-time browser" ,can interface different geospatial data and the application sources such like Academia Sinica historic map and TGOS map, allowing users can easily and conveniently research units on the same platform, three-dimensional, realistic vision of spatio-temporal map and data.

In addition to providing these reference material for local culture education, local cultural recognition, but to further cooperate with scholars, academic experts , local culture-history research worker / team, accumulated rich record of the past, research results, through the spatial database planning, data processing(ex. geocoding), field survey, geospatial materials overlapping, such as nesting geospatial technology to compile the cultural information and value-added applications.

\section{REFERENCES}

Ichun,F.,Fiorella,A.,2014,Atlas of the 2012 Religious Processions in the Tainan Region,Center for Geographic Information Science, Research Center for Humanities and Social Sciences, Academia Sinica,Taiwan.

Pochan,C.,Lingfan,C.,Tachien.C.,Jrlie,J,.2014.Exploring Social Structure of the Kunming Yangfutou Cemetery by Spatial Analyses. Journal of Archaeology and Anthropology, 81, pp. 173-204.

Jrlie,J.,Yingfa,H., $\quad$ Hsiungming,L., $\quad$ Ichun,F.,2012, GPS Record:Atlas of 2012 raojingin lo koan in the Tainan Region, 2012 Digital Archives GISci Conference,Taipei,2012-10-16 2012-10-17.

Revised Auguest 2015 